\title{
Reduction of both beta cell death and alpha cell proliferation by dipeptidyl peptidase-4 inhibition in a streptozotocin-induced model of diabetes in mice
}

\author{
Y. Takeda $\cdot$ Y. Fujita $\cdot$ J. Honjo $\cdot$ T. Yanagimachi $~$ \\ H. Sakagami • Y. Takiyama • Y. Makino • A. Abiko • \\ T. J. Kieffer • M. Haneda
}

Received: 17 August 2011 / Accepted: 12 October 2011 /Published online: 10 November 2011

(C) Springer-Verlag 2011

\begin{abstract}
Aims/hypothesis Incretins stimulate insulin secretion in a glucose-dependent manner but also promote pancreatic beta cell protection. Dipeptidyl peptidase-4 (DPP-4) inhibitors are a new glucose-lowering treatment that blocks incretin degradation by DPP-4. We assessed whether DPP-4 inhibition suppresses the progression to hyperglycaemia in a low-dose streptozotocin (STZ)-induced diabetic mouse model, and then investigated how DPP-4 inhibition affects islet function and morphology.

Methods The DPP-4 inhibitor, des-fluoro-sitagliptin (SITA), was administered to mice during and after STZ injections, and in some mice also before STZ.

Results In control mice, STZ resulted in hyperglycaemia associated with impaired insulin secretion and excess glucagon secretion. In SITA-treated STZ mice, these metabolic abnormalities were improved, particularly when SITA administration was initiated before STZ injections. We observed beta cell loss and dramatic alpha cell expansion associated with decreased insulin content and increased glucagon content after STZ administration. In
\end{abstract}

Electronic supplementary material The online version of this article (doi:10.1007/s00125-011-2365-4) contains peer-reviewed but unedited supplementary material, which is available to authorised users.

Y. Takeda $\cdot$ Y. Fujita $(\bowtie) \cdot J$. Honjo $\cdot$ T. Yanagimachi $\cdot$

H. Sakagami $\cdot$ Y. Takiyama $\cdot$ Y. Makino $\cdot$ A. Abiko $\cdot$ M. Haneda

Division of Metabolism and Biosystemic Science,

Department of Internal Medicine, Asahikawa Medical University,

2-1-1-1 Midorigaoka Higashi,

Asahikawa 078-8510, Japan

e-mail: yfujita@asahikawa-med.ac.jp

T. J. Kieffer

Department of Cellular \& Physiological Sciences,

Life Sciences Institute, University of British Columbia,

Vancouver, BC, Canada
SITA-treated mice, islet architecture and insulin content were preserved, and no significant increase in glucagon content was observed. After STZ exposure, beta cell apoptosis increased before hyperglycaemia, and SITA treatment reduced the number of apoptotic beta cells. Interestingly, alpha cell proliferation was observed in nontreated mice after STZ injection, but the proliferation was not observed in SITA-treated mice.

Conclusions/interpretation Our results suggest that the ability of DPP-4 inhibition to suppress the progression to STZ-induced hyperglycaemia involves both alleviation of beta cell death and alpha cell proliferation.

Keywords Alpha cell proliferation - Beta cell death . Dipeptidyl peptidase-4 · Glucagon · Glucose-dependent insulinotropic polypeptide - Glucagon-like peptide-1 . Insulin $\cdot$ Streptozotocin
Abbreviations
DPP-4 Dipeptidyl peptidase-4
GIP Glucose-dependent insulinotropic polypeptide
GLP-1 Glucagon-like peptide-1
GSIS Glucose-stimulated insulin secretion
PCNA Proliferating cell nuclear antigen
STZ Streptozotocin

\section{Introduction}

Type 2 diabetes mellitus is a metabolic disease characterised by chronic hyperglycaemia which is due to insufficient insulin secretion from pancreatic beta cells and insulin resistance in peripheral tissues. A major goal of therapies is to prevent the increase in mortality attributed to diabetic complications such 
as cardiovascular disease and end-stage renal failure. Beta cell dysfunction progresses to a reduction in beta cell mass, which is caused by beta cell death in diabetic patients [1,2], and ultimately many patients with type 2 diabetes are treated with exogenous insulin. Notably, it has been reported that impaired insulin secretion contributes more to the pathophysiology of Japanese and Asian diabetic patients than of white patients, who are more generally characterised by obesity and insulin resistance [3, 4].

The incretin hormones, glucose-dependent insulinotropic polypeptide (GIP) and glucagon-like peptide-1 (GLP-1), are gastrointestinal peptides secreted from intestinal endocrine cells in response to meal ingestion which stimulate insulin secretion in a glucose-dependent manner. These hormones also promote beta cell proliferation and survival, and inhibit beta cell apoptosis in animals [5, 6]. The enzyme dipeptidyl peptidase-4 (DPP-4) degrades incretins upon their secretion from small intestinal cells $[5,6]$. Therefore new glucoselowering treatments using DPP-4-resistant GLP-1 receptor agonists and DPP-4 inhibitors can be expected to have protective effects on beta cells in human patients. Indeed, it has been reported that sitagliptin, a DPP-4 inhibitor, not only improves glucose metabolism but also protects beta cells, promotes islet neogenesis, and prolongs islet graft survival in rodent diabetic models [7-9]. Furthermore, DPP-4 inhibitors have been reported to delay or suppress the occurrence of hyperglycaemia in an animal model of spontaneous diabetes [10], but the mechanisms have not been completely elucidated.

Here, we assessed whether DPP-4 inhibition can suppress the progression to hyperglycaemia in a streptozotocin (STZ)-induced diabetic mouse model characterised by relatively slow-onset diabetes, selective beta cell death and ultimately hyperglycaemia attributed to insulin deficiency $[11,12]$. We further investigated how DPP-4 inhibition benefits islet function and morphology and improves glucose metabolism in STZ-treated mice using in vivo and in vitro experiments.

\section{Methods}

Animals Six-week-old male C57BL/6 mice were purchased from CLEA Japan (Tokyo, Japan) and housed under a $12 \mathrm{~h}$ light/dark cycle with free access to food and water. All procedures were performed in accordance with Asahikawa Medical University guidelines for the use of animals, with the approval of the university committee.

Research design and generation of STZ-induced diabetic mice Des-fluoro-sitagliptin (SITA) was provided by Merck \& Co. (Whitehouse Station, NJ, USA) and pre-mixed at $4 \mathrm{~g} / \mathrm{kg}$ of normal chow (Purina no. 5015) by Research Diet
(New Brunswick, NJ, USA). Mice were fed either a normal rodent chow diet (designated N, Purina rodent chow no. 5015 ) or a mixed rodent chow diet (designated $\mathrm{S}$, diet containing SITA), ad libitum for 14 days before five consecutive intraperitoneal injections of STZ $(50 \mathrm{mg} / \mathrm{kg}$; Sigma Chemical, St Louis, MO, USA) dissolved in sodium citrate buffer or vehicle alone (further details are provided in Electronic supplementary material [ESM] Fig. 1a). The mice were then maintained on the same initial diets for an additional 20 days of observation (groups $\mathrm{NN}$ and SS), while one cohort was transitioned from the normal diet to the SITA diet during and after STZ injections (group NS). Additional cohorts of mice were treated as above but killed 1 day after the last STZ injection for islet analysis (ESM Fig. 1b). Another group was treated with exendin-4 (EX; $48 \mathrm{nmol} \mathrm{kg}{ }^{-1}$ day $^{-1}$ intraperitoneal injection once a day) to compare 'incretin' action on islets with SITA.

Blood glucose, body weight and glycated haemoglobin Nonfasted blood was collected from the tail vein, and blood glucose levels were measured at 10:00 hours with a Onetouch Ultra glucometer (Lifescan Japan, Tokyo, Japan) on days 1, 15 (the first day of STZ injection), 19 (the last day of STZ injection), 32 (2 weeks after last STZ injection) and 39. Body weight was determined at the time of glucose measurement. $\mathrm{HbA}_{1 \mathrm{c}}$ levels were measured using a DCA Vantage Analyzer (Siemens, Munich, Germany) on blood collected from the tail vein on day 38 .

OGTT and glucose-stimulated insulin secretion We performed an OGTT on day 29 and 2 weeks after initiating the STZ injections, when mice may show raised blood glucose levels as previously reported [13]. Mice were fasted for 16-18 $\mathrm{h}$ before the OGTT. Blood glucose levels were measured at $0,10,30,60$ and 120 min after oral glucose delivery ( $2 \mathrm{~g} / \mathrm{kg}$ body weight). For plasma insulin determinations, blood samples (each $30 \mu \mathrm{l}$ ) were collected from the tail vein into heparinised packed cell volume tubes at 0 and $10 \mathrm{~min}$. Collected samples were separated by centrifugation at $4^{\circ} \mathrm{C}$ and stored at $-20^{\circ} \mathrm{C}$ until assay. Plasma insulin levels were measured using a mouse insulin ELISA kit (Morinaga Institute of Biological Science, Yokohama, Japan) according to the instructions. We determined glucose-stimulated insulin secretion (GSIS) by calculating the difference in insulin concentration at 0 and $10 \mathrm{~min}$ after the glucose load.

Plasma insulin, glucagon, GLP-1 and GIP At day 39, mice were killed after the last glucose and body weight measurement, and blood samples $(200 \mu \mathrm{l})$ were collected after $16-18 \mathrm{~h}$ of fasting for plasma insulin and glucagon assays, and at $10 \mathrm{~min}$ after refeeding for plasma GLP-1 and GIP assays. Collected blood samples were mixed with a $10 \%$ volume of cooled saline containing $12.5 \mathrm{mg} / \mathrm{ml}$ 
EDTA-2Na and 5,000 units/ml aprotinin. These were immediately separated by centrifugation at $4{ }^{\circ} \mathrm{C}$ and stored at $-20^{\circ} \mathrm{C}$. Plasma insulin levels were assayed as described above, and plasma glucagon levels were assayed using a glucagon EIA kit (Yanaihara Institute, Fujinomiya, Japan) according to the instructions. The EIA kit detects pancreatic glucagon and does not cross-react with enteroglucagon, GLP-1 and GLP-2. Active GLP-1 and GIP levels were measured by bioassay as previously described $[14,15]$.

Antibodies and peptides We used guinea pig antibody to insulin (Millipore, Billerica, MA, USA), mouse antibody to glucagon (Sigma-Aldrich Japan, Tokyo, Japan), rabbit antibody to glucagon (Cell Signaling Technology Japan, Tokyo, Japan), mouse antibody to proliferating cell nuclear antigen (PCNA) (BD Biosciences, Tokyo, Japan), and rabbit cleaved caspase-3 antibody (Cell Signaling Technology Japan) as primary antibodies. Alexa Fluor 488 anti-guinea pig IgG, antirabbit IgG, Alexa Fluor 594 anti-mouse IgG (Invitrogen, Carlsbad, CA, USA), and biotinylated goat anti-rabbit $\mathrm{IgG}$ (Vector Laboratories, Burlingame, CA, USA) were used as secondary antibodies. GLP-1(7-36)amide was purchased from Bachem (Torrance, CA, USA). GIP(1-42) was purchased from American Peptide Company (Sunnyvale, CA, USA), and exendin-4 was purchased from Tocris Bioscience (Ellisville, MO, USA).

Immunohistochemistry Pancreas was resected immediately after death at day 20 or 39 , and fixed in $4 \%$ paraformaldehyde in PBS overnight at $4{ }^{\circ} \mathrm{C}$ and then embedded in paraffin blocks after an ethanol wash. Embedded tissue was sliced into $3 \mu \mathrm{m}$ thick sections and deparaffinised with a series of xylene and ethanol. We performed antigen retrieval with sodium citrate buffer $(10 \mathrm{mmol} / 1$ sodium citrate containing $0.05 \%$ Tween $20, \mathrm{pH} 6.0$ ) followed by microwave heating and treatment of sections with a reagent for blocking non-specific background staining (Dako Japan, Tokyo, Japan). Slides were incubated with primary antibody overnight at $4^{\circ} \mathrm{C}$, and, after they had been washed, they were incubated with secondary antibody for $2 \mathrm{~h}$ at room temperature in the shade. They were then washed and finally mounted in aqueous medium with DAPI (Vectashield Mounting Medium with DAPI; Vector Laboratories). Stained sections were observed under fluorescence microscopy (BZ-8100; Keyence, Osaka, Japan), and digital images were collected. Other sections were also immunostained using an avidin/biotin complex immunoperoxidase method with 3,3'-diaminobenzidine after antigen retrieval and treatment with hydrogen peroxide. We performed counter staining with haematoxylin in this method.

Islet morphometry We measured the insulin- and glucagonpositive cell area, as well as islet area using commercial software (BZ Analyzer; Keyence), and assigned these as beta cell area, alpha cell area and islet area, respectively. We also counted the number of insulin-positive cells, glucagon-positive cells, and total islet cells according to DAPI (nuclear) staining. All morphometry studies were conducted in a blinded fashion.

Determination of cell proliferation and cell death in vivo Insulin and PCNA double positive cells were assigned as beta cell proliferation, and glucagon and PCNA double positive cells were assigned as alpha cell proliferation. Apoptotic beta cells were determined by cleaved caspase-3positive and TUNEL-positive cells and adjusted for beta cell area in serial sections stained with insulin. TUNEL staining was performed using a commercial apoptotic cell detection kit (In Situ Cell Death Detection Kit, TMR red; Roche Diagnostics Japan, Tokyo, Japan).

Pancreatic insulin/glucagon contents Pancreas was extracted by an acid/ethanol method. The tissue was placed in acid/ethanol $(1.5 \% \mathrm{HCl}$ in $70 \%$ ethanol $)$ and incubated overnight at $-20^{\circ} \mathrm{C}$. Then, pancreas was homogenised and incubated overnight. Homogenised samples were centrifuged at 2,000 rpm for $15 \mathrm{~min}$ at $4^{\circ} \mathrm{C}$, and the supernatant fraction was transferred to a new vial. Samples were neutralised with the same volume of $1 \mathrm{~mol} / 1 \mathrm{Tris} / \mathrm{HCl}$ (pH 7.5), and diluted $1: 100$ or 1:1,000 with PBS containing $0.1 \%$ BSA. Insulin and glucagon concentrations were measured using EIA kits as described above, and adjusted for protein concentration (BCA, Pierce Protein Research, Rockford, IL, USA).

In vitro STZ-induced beta cell apoptosis The mouse insulinoma cell line, MIN6, was maintained in DMEM (25 mmol/l glucose) with 10\% FBS (Invitrogen Japan, Tokyo, Japan), $100 \mathrm{IU} / \mathrm{ml}$ penicillin and $100 \mu \mathrm{g} / \mathrm{ml}$ streptomycin (Invitrogen Japan) at $37^{\circ} \mathrm{C}$ in $5 \% \mathrm{CO}_{2}$. MIN6 cells were cultured in DMEM for $48 \mathrm{~h}$, after which medium was replaced with serum-free medium containing $0.2 \%$ BSA (Sigma-Aldrich Japan) and $10 \mathrm{nmol} / 1 \mathrm{GLP}-1$ $\left(7-36_{\mathrm{NH} 2}\right)$ and/or $10 \mathrm{nmol} / 1 \mathrm{GIP}(1-42)$. At $2 \mathrm{~h}$ after the addition of GLP-1 and GIP, we treated cells with 1, 3 or $5 \mathrm{mmol} / \mathrm{l} \mathrm{STZ}$, and incubated them for an additional $8 \mathrm{~h}$. After incubation with STZ, the cells were fixed in $4 \%$ paraformaldehyde in PBS and then stained using the Roche apoptotic cell detection kit as mentioned above. Apoptotic cells were determined by counting the number of nuclei with positive TUNEL staining in 500 random cells.

Statistical analysis Data are expressed as mean \pm SEM. Statistical analysis was performed using one-way ANOVA followed by the Bonferroni or Dunnett multiple comparison 
post test. Data were analysed using commercial software (Prism 5; GraphPad, San Diego, CA, USA). $p<0.05$ was considered significant.

\section{Results}

DPP-4 inhibition reduced hyperglycaemia in STZ mice First we examined if SITA treatment in the diet can increase active GLP-1 and GIP via DPP-4 inhibition in mice. Both active GLP-1 and GIP levels were significantly $(p<0.05)$ increased by SITA treatment (GLP-1: NN 60.6 $19.2 \mathrm{pmol} / 1$ vs SS $177.9 \pm 41.7 \mathrm{pmol} / \mathrm{l}$; GIP: NN $165.8 \pm 76.3 \mathrm{pmol} / 1$ vs SS $2185.0 \pm 734.1 \mathrm{pmol} / \mathrm{l} ; n=7)$.

There was no significant difference in fed blood glucose levels among all experimental groups including non-diabetic controls before and during STZ treatment (Fig. 1a). Thereafter, we observed marked hyperglycaemia in non-treated diabetic control mice (NN group), whereas blood glucose levels were significantly reduced in mice maintained throughout on SITA (SS group) (19.9 $\pm 1.8 \mathrm{vs} 29.8 \pm 2.2 \mathrm{mmol} / \mathrm{l}$ at day $32, p<0.01$, and $17.1 \pm 1.8$ vs $29.0 \pm 2.3 \mathrm{mmol} / \mathrm{l}$ at day $39, p<0.001)$ and also in mice that were transitioned to the SITA diet during the STZ injections (NS group) $(22.5 \pm 2.6$ vs $29.8 \pm 2.2 \mathrm{mmol} / 1$ at day 32, $p<0.05$, Fig. 1a). Body weight increased throughout the study in non-diabetic control mice, whereas mice injected with STZ lost weight irrespective of the treatment (Fig. 1b).

We observed a significant increase in $\mathrm{HbA}_{1 \mathrm{c}}$ levels in NN mice compared with non-diabetic control mice on day 38, while in both SITA-treated cohorts (NS and SS), $\mathrm{HbA}_{1 \mathrm{c}}$ levels were significantly lower than in $\mathrm{NN}$ mice $(3.7 \pm 0.1 \%[16.9 \pm 1.4 \mathrm{mmol} / \mathrm{mol}]$ in controls $(\mathrm{C})$, $5.6 \pm 0.2 \%[37.2 \pm 2.5 \mathrm{mmol} / \mathrm{mol}]$ in $\mathrm{NN}, 4.5 \pm 0.2 \%$ $[25.7 \pm 2.5 \mathrm{mmol} / \mathrm{mol}]$ in $\mathrm{NS}$, and $3.9 \pm 0.2 \%$ [18.6 $\pm 2.5 \mathrm{mmol} / \mathrm{mol}]$ in SS; Fig. 1c). These results demonstrate that chronic hyperglycaemia was dramatically improved by SITA treatment in low-dose STZ mice, particularly when SITA was started before STZ injections. a

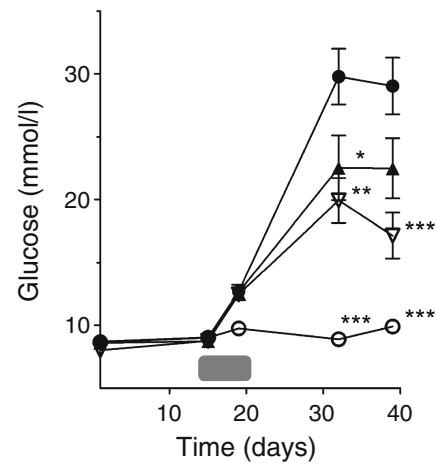

b

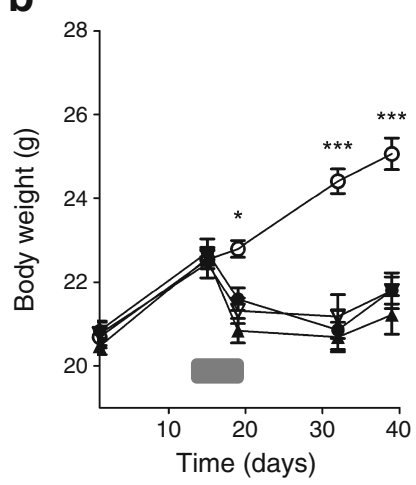

C

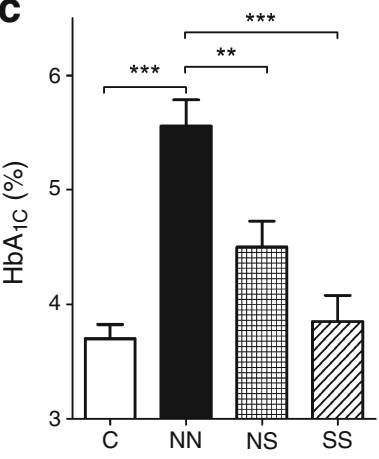

d

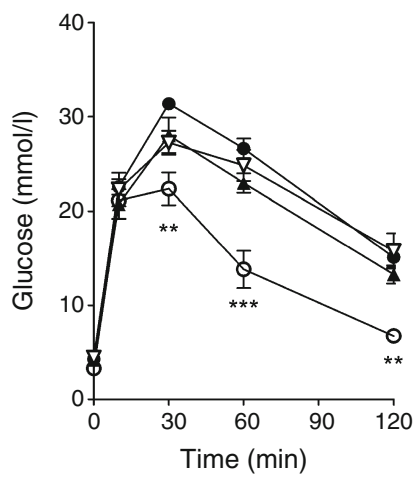

e

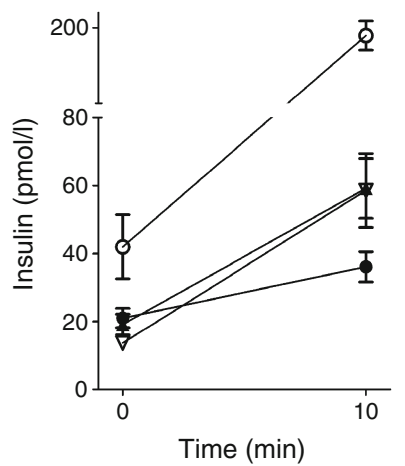

f

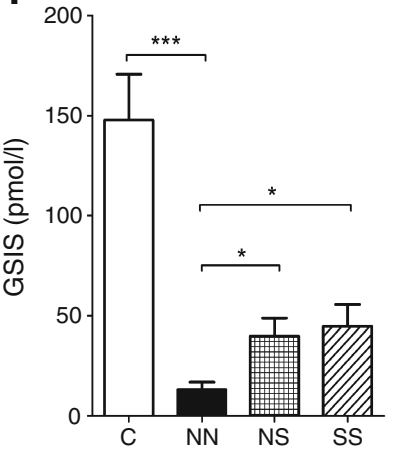

g

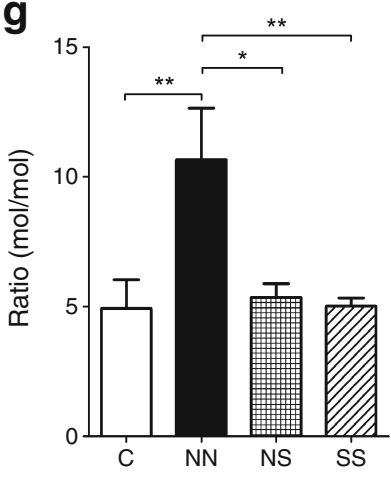

Fig. 1 DPP-4 inhibition improves hyperglycaemia, alleviates the decrease in GSIS, and suppresses the excess of glucagon secretion in low-dose STZ mice. Fed blood glucose levels (a) and body weight (b) measured at day $1,15,19,32$ and $39(n=13-15$ in each group). c $\mathrm{HbA}_{1 \mathrm{c}}$ levels at day $38(n=9-10)$. To convert values for $\mathrm{HbA}_{1 \mathrm{c}}$ in per cent into millimoles per mole, subtract 2.15 and multiply by 10.929 . d Blood glucose levels after $2 \mathrm{~g} / \mathrm{kg}$ oral glucose $(n=4-9)$. e Plasma

insulin levels at 0 and 10 min after glucose load $(n=8-10)$. f GSIS determined by calculating the difference in insulin levels between 0 and 10 min after glucose load $(n=8-10)$. g Fasted plasma glucagon/insulin ratio at day $39(n=6)$. The data are presented as means \pm SEM. ${ }^{*} p<0.05$, ${ }^{* *} p<0.01,{ }^{* * *} p<0.001$ vs NN. White circles, C (control); black circles, $\mathrm{NN}$; black triangles, NS; inverted triangles, SS; grey horizontal bar, treatment with STZ or vehicle 
DPP-4 inhibition improved GSIS We performed OGTTs to evaluate glucose tolerance and insulin secretion and determined GSIS by measuring the difference in insulin concentrations between 0 and $10 \mathrm{~min}$ after the glucose load. Blood glucose levels after the glucose load were slightly increased in the diabetic controls (Fig. 1d). While GSIS after the oral glucose load was dramatically impaired as expected in NN mice, it was significantly higher in SITAtreated NS and SS mice compared with NN mice (Fig. 1e, f). Thus DPP-4 inhibition partially alleviated the decrease in GSIS in low-dose STZ mice.

DPP-4 inhibition suppressed the increase in glucagon/ insulin ratio We measured fasted plasma insulin and glucagon levels at day 39 to assess the degree of inappropriate glucagon secretion during diabetes. The glucagon/insulin ratio was higher in diabetic NN control mice compared with non-STZ-injected mice (C cohort), while the ratio was significantly lower in both SITA-treated cohorts (NS and SS) compared with NN mice (Fig. 1g).

DPP-4 inhibition protected islet morphology in STZ mice To evaluate the effect of DPP-4 inhibition on islet morphology in STZ-injected mice, we examined insulin and glucagon double immunofluorescence staining (Fig. 2a-d). Insulin-positive beta cell area was markedly reduced and glucagon-positive alpha cell area was strikingly increased in diabetic control mice (NN cohort) compared with non-diabetic control mice (C cohort) (Fig. 2a, b, e, g). However, in SITA-treated mice, especially the SS group which started SITA before STZ injections, beta cell area was increased and alpha cell area was significantly reduced compared with NN mice (Fig. 2c, d, e, g). We also observed reduced beta cell number and increased alpha cell number in NN mice similarly to beta cell and alpha cell area, whereas beta cell number was significantly increased and alpha cell number was significantly reduced in SITA-treated mice (Fig. 2f, h). These results indicate that DPP-4 inhibition with SITA not only protected against beta cell reduction but also suppressed alpha cell expansion in mice injected with low-dose STZ.

$D P P-4$ inhibition alleviated the reduction in insulin content and suppressed the increase in glucagon content in STZ mice In agreement with the above observations, we observed that pancreatic insulin content was markedly reduced in diabetic control mice (NN group) compared with non-diabetic controls (C group), while it was significantly higher in mice treated with SITA compared with NN mice (Fig. 3a). Moreover, pancreatic glucagon content was increased in NN mice compared with non-diabetic controls, while it was significantly lower in SITA-treated mice compared with NN mice (Fig. 3b).
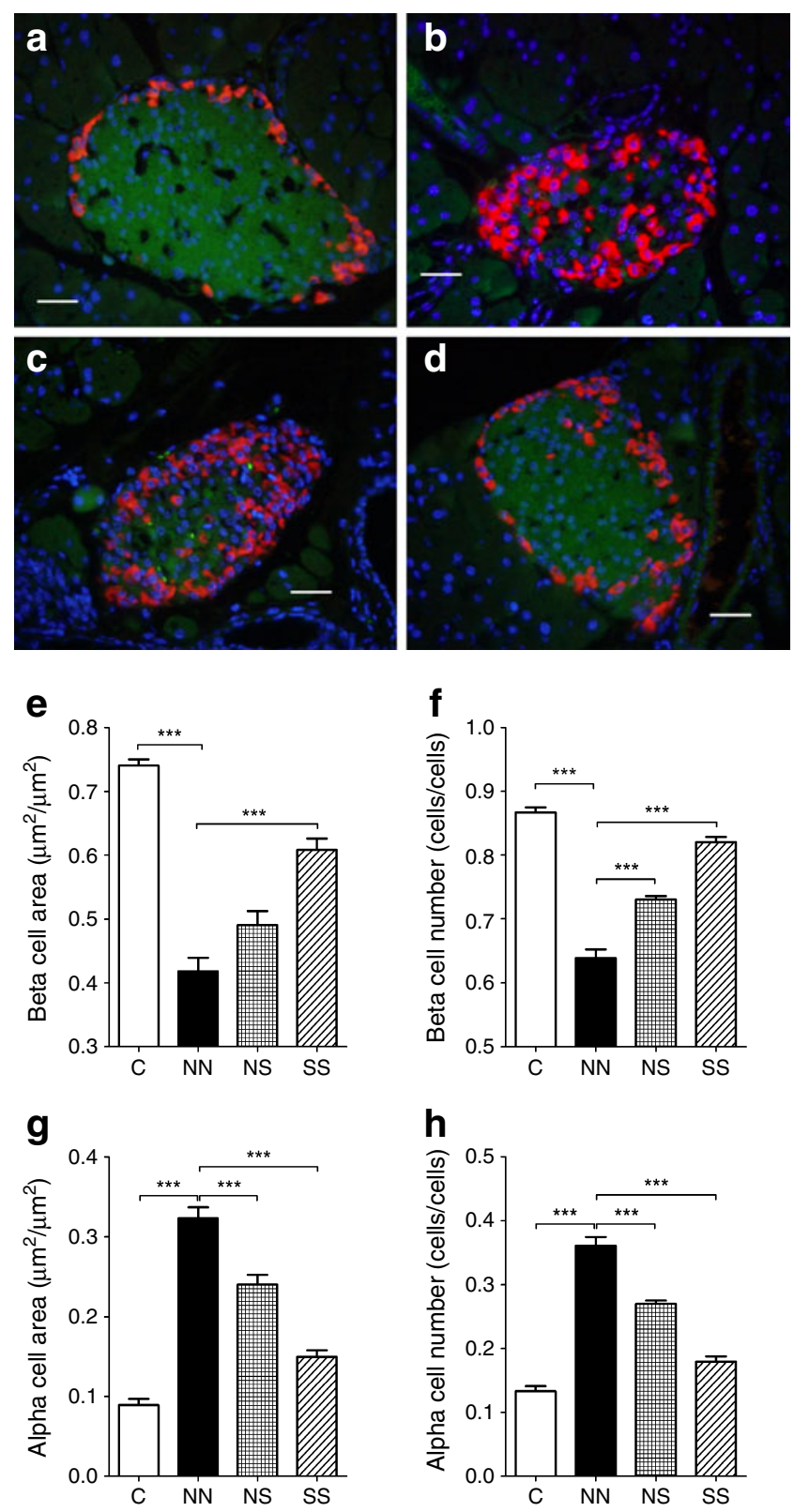

Fig. 2 DPP-4 inhibition reduces beta cell loss and alpha cell expansion in low-dose STZ mice. Morphological changes in pancreatic islets in lowdose STZ mice at day 39. Pancreatic sections were stained by insulin (green), glucagon (red) and DAPI (blue), with representative islets shown (scale bar, $30 \mu \mathrm{m}$, magnification $\times 800$ ). a Non-diabetic control $(\mathrm{C})$. b Diabetic control (NN). c SITA-treated diabetic (NS). d SITA-treated diabetic (SS). e Insulin-positive beta cell area per islet area $(n=4-5)$. f Beta cell number per islet cell number $(n=4-5)$. $\mathbf{g}$ Glucagon-positive alpha cell area per islet area $(n=4-5)$. $\mathbf{h}$ Alpha cell number per islet cell number $(n=4-5)$. The data are presented as means \pm SEM. ${ }^{* * *} p<0.001$ vs NN

Alpha cell proliferation occurred in STZ mice, but DPP-4 inhibition suppressed the proliferation We observed alpha cell expansion including increased alpha cell number and pancreatic glucagon content accompanied by beta cell reduction in response to low-dose STZ injections. Hence, 

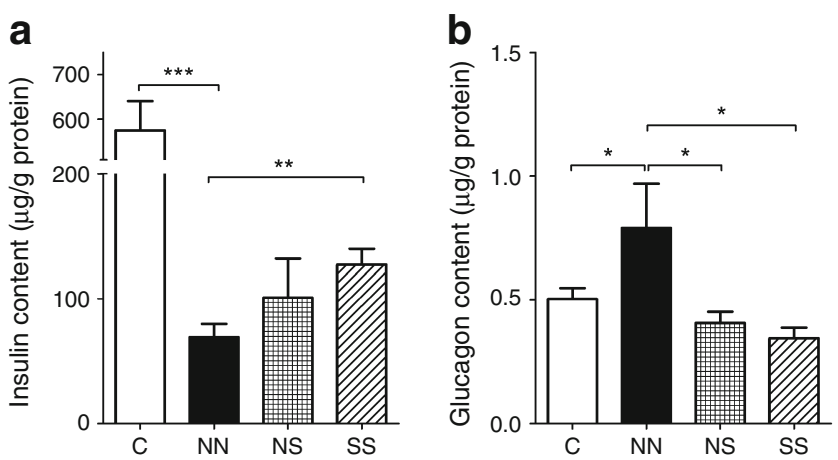

Fig. 3 DPP-4 inhibition increases pancreatic insulin content and reduces glucagon content in low-dose STZ mice. Pancreatic insulin content (a) $(n=9-10)$ and glucagon content $(\mathbf{b})(n=6)$ at day 39 . The data are presented as means \pm SEM. ${ }^{*} p<0.05,{ }^{* *} p<0.01,{ }^{* * *} p<0.001$ vs NN

we performed glucagon and PCNA double immunofluorescence staining to quantify alpha cell proliferation (ESM Fig. 2a-d). Glucagon/PCNA double positive cells in islets were significantly increased in diabetic control mice (NN cohort) compared with non-diabetic control mice (C cohort), whereas such double positive cells were significantly reduced in SITA-treated NS and SS cohorts compared with NN mice (ESM Fig. 2e). These results indicate that alpha cell proliferation occurred in STZ mice, and this was inhibited by SITA.

Both beta cell death and alpha cell proliferation were observed immediately after STZ injection in mice, but these changes were suppressed by DPP-4 inhibition To further assess the protective effect of SITA on islets in STZ mice, we conducted immunohistochemical analysis 1 day after the last STZ injection (day 20), at a time when no overt hyperglycaemia was apparent (ESM Fig. 2f). We also compared the protective effects on islets between treatment with SITA and the GLP-1 receptor agonist exendin-4 (EX). The NN and SS groups exhibited a $30 \%$ increase in food consumption compared with non-diabetic controls (C), while the EX group had similar food consumption to $\mathrm{C}$. We assessed beta cell death using two different types of immunostaining: (1) cleaved caspase-3, which plays a key role in the apoptotic pathway; (2) TUNEL staining, which detects DNA fragmentation. Cleaved caspase-3-positive cells and TUNEL-positive cells in islets were significantly increased by injection of STZ (NN mice compared with C mice), while in the SS and EX cohorts (treated with SITA and exendin-4, respectively), apoptotic cells were significantly reduced compared with $\mathrm{NN}$ mice (Figs 4 and 5a, b). There was an increase in insulin/ PCNA double positive cells in exendin-4-treated mice compared with the NN group, but this did not reach statistical significance (Fig. 5c). Notably, glucagon/PCNA double-positive cells were strikingly increased following STZ injection in the $\mathrm{NN}$ mice, and this was significantly

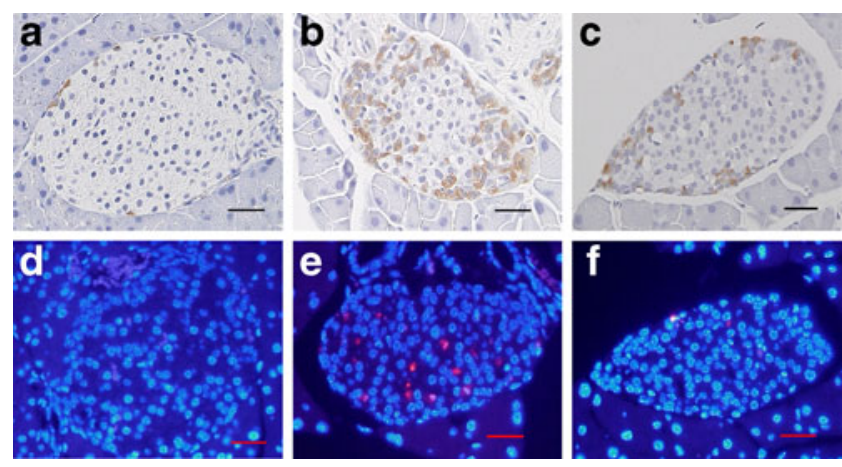

Fig. 4 DPP-4 inhibition reduces beta cell death in low-dose STZ mice. Pancreatic sections stained with cleaved caspase-3 and TUNEL to detect apoptotic cell death in mice 1 day after the last STZ injection (at day 20). a-c Cleaved caspase-3 (brown) immunostaining. d-f TUNEL staining (red, TUNEL positive; blue, DAPI). a, $\mathbf{d} \mathrm{C}$ as nondiabetic control mice. b, e NN as diabetic control mice. c, f SS as SITA-treated diabetic mice. Bar $=30 \mu \mathrm{m}$. Magnification, $\times 800$

reduced towards control levels by SITA treatment (SS cohort; ESM Fig. 2g). These results clearly indicate that STZ exposure acutely results in beta cell death and dramatic alpha cell proliferation. In addition, SITA protects beta cells from STZ-induced cell death as well as exendin-4, and SITA
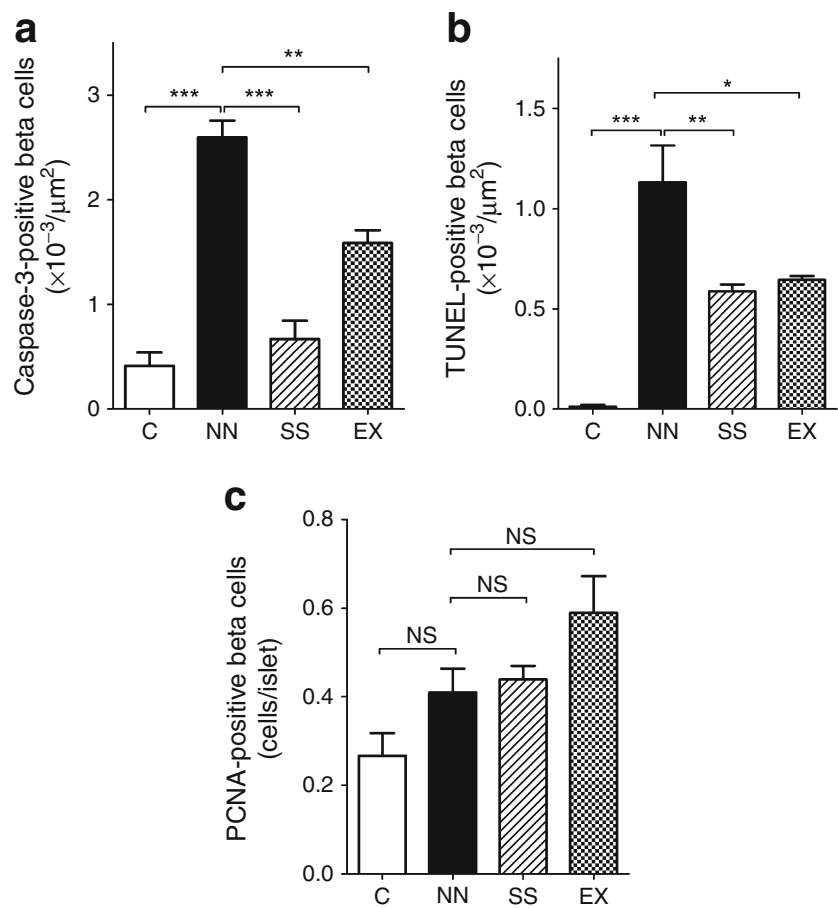

Fig. 5 DPP-4 inhibition suppresses beta cell apoptosis equivalently with pharmacological GLP-1 agonism in low-dose STZ mice. a Cleaved caspase-3-positive cells determined by counting caspase3 -positive cells and adjusting for beta cell area in serial sections stained with insulin ( $n=3$ in each group) at day 20. b TUNEL-positive cells. TUNEL-positive cells were determined similarly to caspase-3positive cells $(n=3)$. c PCNA-positive beta cells as a marker of beta cell proliferation $(n=3)$. The data are presented as means \pm SEM. ${ }^{*} p<$ $0.05, * * p<0.01, * * * p<0.001$ vs NN 
also suppresses alpha cell proliferation immediately after STZ exposure. Moreover, our results indicate that SITA treatment attenuated beta cell loss in STZ mice via antiapoptotic effects rather than by proliferative effects.

GLP-1 and GIP equivalently suppressed STZ-induced apoptosis in MIN6 beta cells Since enhanced activity of GLP-1 and GIP is thought to be the primary mechanism of islet actions of DPP-4 inhibition, we further examined whether GLP-1 and GIP can directly protect beta cells from STZ-induced cell death in vitro using the MIN6 beta cell line. We determined the extent of MIN6 cell apoptosis by counting the number of cells with positive TUNEL staining. STZ induced apoptosis in MIN6 cells in a concentration-dependent manner (ESM Fig. 3). GLP-1 and GIP equivalently and effectively suppressed MIN6 cell apoptosis induced by STZ at each concentration examined (ESM Fig. 3). Interestingly, GLP-1 and GIP additively suppressed MIN6 cell apoptosis by $5 \mathrm{mmol} / 1 \mathrm{STZ}$ treatment (ESM Fig. 3).

\section{Discussion}

DPP-4 inhibitors are a new class of oral glucose-lowering agents that act to block GIP and GLP-1 degradation by DPP-4 activity, and thereby enhance insulin secretion in a glucose-dependent manner. Incretin hormones also have protective effects on pancreatic beta cells by promoting cell survival and proliferation, and inhibiting cell death $[5,6]$, but whether the same benefits can be realised in humans remains to be determined. In the present study, we determined that placing the DPP-4 inhibitor, SITA, in rodent chow effectively raised active GLP-1 and GIP levels. We then demonstrated that DPP-4 inhibition reduced the progression to overt hyperglycaemia and alleviated the reduction in glucose-stimulated insulin secretion in lowdose STZ mice. In addition, we found that SITA treatment reduced the increased glucagon/insulin ratio that ensued rapidly after STZ injections, and, undoubtedly, this contributed to the glucose-lowering action of SITA in this model of diabetes. In diabetes, inappropriate glucagon secretion in fasting and postprandial states contributes to hyperglycaemia [16-23], besides impaired insulin secretion attributed to beta cell failure. Although we could not clarify the precise mechanism of how SITA reduced the relative glucagon secretion, we assume that SITA-mediated enhanced levels of endogenous active GLP-1 may have suppressed glucagon secretion from alpha cells, as previously reported [24]. In association with modest preservation of beta cell mass and insulin content in SITA-treated mice, we observed a reduction in STZ-induced alpha cell expansion and associated increased glucagon content with
SITA treatment. Therefore SITA may contribute to both beta cell protection and regulation of alpha cell number in STZ mice. A recent study reported that DPP-4 inhibitor regulation of glycaemia, insulin secretion and glucagon secretion involves not only enhancement of active GLP-1 and GIP levels but also reduced liberation of the bioactive dipeptides, His-Ala and Tyr-Ala, generated by DPP-4 [25]. Therefore, additional mechanisms besides the enhancement of bioactive incretin levels may contribute to the improvement in glycaemia we observed in this study.

To directly investigate the protective effects of DPP-4 inhibition on islets, we conducted immunohistochemical analysis after STZ injection but before marked hyperglycaemia occurred. Apoptotic cells, with positive cleaved caspase-3 or TUNEL staining, were increased in nontreated STZ mice, whereas these apoptotic cells were significantly reduced in SITA-treated mice equivalently to mice treated with exendin-4, a GLP-1 receptor agonist. On the other hand, we did not observe a significant increase in PCNA-positive beta cells in SITA-treated mice. These results suggest that DPP-4 inhibition with SITA may primarily protect beta cell mass via an antiapoptosis mechanism rather than induction of cell proliferation or replication.

We performed in vitro studies using MIN6 beta cells to confirm the direct antiapoptotic effects of incretins on beta cell protection from STZ-mediated toxicity. STZ induced apoptosis in MIN6 cells in a concentration-dependent manner, and both GLP-1 and GIP equivalently suppressed MIN6 cell apoptosis. Intriguingly, GLP-1 and GIP additively suppressed MIN6 cell apoptosis on exposure to the highest dose of STZ. These findings are in agreement with previous studies showing that both GLP-1 and GIP receptor signalling can suppress apoptosis in beta cell lines induced by cytotoxic agents [26-31]. In addition to the common antiapoptotic pathways of GLP-1 and GIP signalling [6, 26-31], different pathways [32-36] may promote additive antiapoptotic effects on beta cells, as observed in our analysis of STZ-induced apoptosis studies with MIN6 beta cells.

Interestingly, we observed considerable alpha cell expansion with increased pancreatic glucagon content in nontreated low-dose STZ mice compared with non-diabetic control mice. In addition, PCNA-positive alpha cells in islets were significantly increased in non-treated diabetic mice compared with control mice, indicating alpha cell proliferation in the diabetic mice. In addition to the apparent functional abnormality of alpha cells that results in inappropriate glucagon secretion, there are previous reports of apparent alpha cell expansion in diabetic humans [37-41] and rodents [42, 43], which may contribute to raised glucagon levels. Although alpha cell expansion is commonly observed after beta cell loss, the mechanisms 
regulating alpha cell number under physiological and diabetic conditions are not well understood. IL-6 stimulates alpha cell proliferation in a high-fat diet fed state with insulin resistance [44], and glucagon receptor knockout mice display alpha cell hyperplasia [45]. In Psammomys obesus, alpha cell expansion was observed in association with elevated pancreatic GLP-1 [46] after diet-induced hyperglycaemia.

In our study using the beta cell toxin, STZ, pancreatic alpha cells proliferated concomitantly with beta cell death after STZ exposure yet before significant elevation of blood glucose levels. These findings suggest that alpha cell proliferation is not caused by hyperglycaemia. Decreased insulin action in pancreatic alpha cells leads to enhanced glucagon secretion [47]. Therefore it is possible that local insulin deficit in islets caused by beta cell loss leads to pancreatic alpha cell proliferation. Interestingly, Thorel et al. showed that alpha cells can be converted into beta cells under conditions of extreme damage to beta cells [48]. Also, alpha cell proliferation and elevated glucagon levels may aid in the formation of new beta cells, since pancreatic glucagon is required for beta cell formation and differentiation [49]. Moreover, recent studies have shown that alpha cells are a source of both GLP-1 and GIP, raising the potential of their involvement in regulation of beta cell mass and function $[14,46]$. It is interesting to consider that incretins, secreted not only from the gastrointestinal tract but also from pancreatic islets, may coordinately regulate islet function and morphology. Therefore we suggest that DPP-4 inhibition may enhance incretin function locally in islets and may thereby contribute to their effectiveness in diabetes.

In conclusion, our present study indicates that DPP-4 inhibition with SITA suppresses the progression to overt hyperglycaemia in mice given low-dose STZ with alleviation of both beta cell death and alpha cell proliferation. Whether early use of DPP-4 inhibitors can suppress the progression to overt diabetes in humans warrants investigation.

Acknowledgements We thank MSD Merck \& Co. (Whitehouse Station, NJ, USA) for providing des-fluoro-sitagliptin and supporting the research fund. We also thank J-i. Miyazaki (Osaka University, Japan) for providing MIN6 cells.

Contribution statement Y Takeda, YF, JH, TY, HS, Y Takiyama, YM, AA, TJK, MH contributed to the study concept and design; Y Takeda, YF, JH, TY acquired the data; Y Takeda, YF, JH, TY, HS, Y Takiyama, YM, AA, TJK, MH analysed and interpreted the data and performed statistical analysis; $\mathrm{Y}$ Takeda, YF drafted the manuscript; Y Takeda, YF, JH, TY, HS, Y Takiyama, YM, AA, TJK, MH reviewed the manuscript for important intellectual content; YF obtained funding; MH supervised the study.

Duality of interest The authors declare that there is no duality of interest associated with this manuscript.

\section{References}

1. Butler AE, Janson J, Bonner-Weir S, Ritzel R, Rizza RA, Butler PC (2003) $\beta$-Cell deficit and increased $\beta$-cell apoptosis in humans with type 2 diabetes. Diabetes 52:102-110

2. Mathis D, Vence L, Benoist C (2001) $\beta$-cell death during progression to diabetes. Nature 414:792-798

3. Tripathy D, Carlsson M, Almgren P et al (2000) Insulin secretion and insulin sensitivity in relation to glucose tolerance: lessons from the Botnia Study. Diabetes 49:975-980

4. Fukushima M, Usami M, Ikeda M et al (2004) Insulin secretion and insulin sensitivity at different stages of glucose tolerance: a crosssectional study of Japanese type 2 diabetes. Metabolism 53:831-835

5. Drucker DJ (2006) The biology of incretin hormones. Cell Metab 3:153-165

6. Baggio LL, Drucker DJ (2007) Biology of incretins: GLP-1 and GIP. Gastroenterology 132:2131-2157

7. Pospisilik JA, Martin J, Doty T et al (2003) Dipeptidyl peptidase IV inhibitor treatment stimulates $\beta$-cell survival and islet neogenesis in streptozotocin-induced diabetic rats. Diabetes 52:741-750

8. Mu J, Woods J, Zhou YP et al (2006) Chronic inhibition of dipeptidyl peptidase- 4 with a sitagliptin analog preserves pancreatic $\beta$-cell mass and function in a rodent model of type 2 diabetes. Diabetes 55:16951704

9. Kim SJ, Nian C, Doudet DJ, Mclntosh CH (2008) Inhibition of dipeptidyl peptidase IV with sitagliptin (MK0431) prolongs islet graft survival in streptozotocin-induced diabetic mice. Diabetes 57:1331-1339

10. Sudre B, Broqua P, White RB et al (2002) Chronic inhibition of circulating dipeptidyl peptidase IV by FE 999011 delays the occurrence of diabetes in male zucker diabetic fatty rats. Diabetes 51:1461-1469

11. Szkudelski T (2001) The mechanism of alloxan and streptozotocin action in B cells of the rat pancreas. Physiol Res 50:536-546

12. Lenzen S (2008) The mechanisms of alloxan- and streptozotocininduced diabetes. Diabetologia 51:216-226

13. Breyer MD, Böttinger E, Brosius FC 3rd et al (2005) Mouse models of diabetic nephropathy. J Am Soc Nephrol 16:27-45

14. Fujita Y, Wideman RD, Asadi A et al (2010) Glucose-dependent insulinotropic polypeptide is expressed in pancreatic islet $\alpha$-cells and promotes insulin secretion. Gastroenterology 138:1966-1975

15. Riedel MJ, Lee CW, Kieffer TJ (2008) Engineered glucagon-like peptide-1-producing hepatocytes lower plasma glucose levels in mice. Am J Physiol Endocrinol Metab 296:E936-E944

16. Unger RH, Aguilar-Parada E, Müller WA, Eisentraut AM (1970) Studies of pancreatic alpha cell function in normal and diabetic subjects. J Clin Invest 49:837-848

17. Unger RH (1976) The Banting Memorial Lecture 1975. Diabetes and the alpha cell. Diabetes 25:136-151

18. Unger RH (1985) Glucagon physiology and pathophysiology in the light of new advances. Diabetologia 28:574-578

19. Consoli A (1992) Role of liver in pathophysiology of NIDDM. Diabetes Care 15:430-441

20. Baron AD, Schaeffer L, Shragg P, Kolterman OG (1987) Role of hyperglucagonemia in maintenance of increased rates of hepatic glucose output in type 2 diabetics. Diabetes 36:274-283

21. Basu A, Shah P, Nielsen M, Basu R, Rizza RA (2004) Effects of type 2 diabetes on the regulation of hepatic glucose metabolism. J Investig Med 52:366-374

22. Gastaldelli A, Baldi S, Pettiti M et al (2000) Influence of obesity and type 2 diabetes on gluconeogenesis and glucose output in humans: a quantitative study. Diabetes 49:1367-1373

23. Ali S, Drucker DJ (2009) Benefits and limitations of reducing glucagon action for the treatment of type 2 diabetes. Am J Physiol Endocrinol Metab 296:E415-E421 
24. Dunning BE, Foley JE, Ahrén B (2005) Alpha cell function in health and disease: influence of glucagon-like peptide-1. Diabetologia 48:1700-1713

25. Waget A, Cabou C, Masseboeuf M et al (2011) Physiological and pharmacological mechanisms through which the DPP-4 inhibitor sitagliptin regulates glycemia in mice. Endocrinology 152:30183029

26. Trumper A, Trumper K, Horsch D (2002) Mechanisms of mitogenic and anti-apoptotic signaling by glucose dependent insulinotropic polypeptide in $\beta$ (INS-1)-cells. J Endocrinol 174:233-246

27. Hui H, Nourparvar A, Zhao X, Perfetti R (2003) Glucagon-like peptide-1 inhibits apoptosis of insulin-secreting cells via a cyclic 5 '-adenosine monophosphate-dependent protein kinase A- and a phosphatidylinositol 3-kinase dependent pathway. Endocrinology 144:1444-1455

28. Li Y, Hansotia T, Yusta B, Ris F, Halban PA, Drucker DJ (2003) Glucagon-like peptide-1 receptor signaling modulates $\beta$-cell apoptosis. J Biol Chem 278:471-478

29. Ehses JA, Casilla VR, Doty T et al (2003) Glucose-dependent insulinotropic polypeptide promotes $\beta$-(INS-1) cell survival via cyclic adenosine monophosphate-mediated caspase-3 inhibition and regulation of p38 mitogen-activated protein kinase. Endocrinology 144:4433-4445

30. Kwon G, Pappan KL, Marshall CA, Schaffer JE, McDaniel ML (2004) Cyclic AMP dose-dependently prevents palmitate-induced apoptosis by both PKA and cAMP-GEF-dependent pathways in ß-cells. J Biol Chem 279:8938-8945

31. Buteau J, El-Assaad W, Rhodes CJ, Rosenberg L, Joly E, Prentki M (2004) Glucagon-like peptide-1 prevents beta cell glucolipotoxicity. Diabetologia 47:806-815

32. Ferdaoussi M, Abdelli S, Yang JY et al (2008) Exendin-4 protects $\beta$-cells from interleukin-1 $\beta$-induced apoptosis by interfering with the c-Jun $\mathrm{NH}_{2}$-terminal kinase pathway. Diabetes 57:1205-1215

33. Cornu M, Yang JY, Jaccard E, Poussin C, Widmann C, Thorens B (2009) Glucagon-like peptide-1 protects $\beta$-cells against apoptosis by increasing the activity of an IGF-2/IGF-1 receptor autocrine loop. Diabetes 58:1816-1825

34. Cornu M, Modi H, Kawamori D, Kulkani RN, Joffraud M, Thorens B (2010) Glucagon-like peptide-1 increases $\beta$-cell glucose competence and proliferation by translational induction of insulin-like growth factor-1 receptor expression. J Biol Chem 285:10538-10545

35. Widenmaier SB, Sampaio AV, Underhill TM, McIntosh $\mathrm{CH}$ (2009) Noncanonical activation of Akt/protein kinase B in $\beta$ cells by the incretin hormone glucose-dependent insulinotropic polypeptide. J Biol Chem 284:10764-10773
36. Kim SJ, Winter K, Nian C, Tsuneoka M, Koda Y, McIntosh CH (2005) Glucose-dependent insulinotropic polypeptide (GIP) stimulation of pancreatic $\beta$-cell survival is dependent upon phosphatidylinositol 3-kinase (PI3K)/protein kinase B (PKB) signaling, inactivation of the forkhead transcription factor Foxo1, and downregulation of bax expression. J Biol Chem 280:22297-22307

37. Rahier J, Goebbels RM, Henquin JC (1983) Cellular composition of the human diabetic pancreas. Diabetologia 24:366-371

38. Clark A, Wells CA, Buley ID et al (1988) Islet amyloid, increased A-cells, reduced B-cells and exocrine fibrosis: quantitative changes in the pancreas in type 2 diabetes. Diabetes Res 9:151159

39. Sakuraba H, Mizukami H, Yagihashi N, Wada R, Hanyu C, Yagihashi S (2002) Reduced beta-cell mass and expression of oxidative stress-related DNA damage in the islet of Japanese type 2 diabetic patients. Diabetologia 45:85-96

40. Yoon KH, Ko SH, Cho JH et al (2003) Selevtive $\beta$-cell loss and $\alpha$-cell expansion in patients with type 2 diabetes mellitus in Korea. J Clin Endocrinol Metab 88:2300-2308

41. Iki K, Pour PM (2007) Distribution of pancreatic endocrine cells including IAPP-expressing cells in non-diabetic and type 2 diabetic cases. J Histochem Cytochem 55:111-118

42. Hoftiezer V, Carpenter AM (1973) Comparison of streptozotocin and alloxan-induced diabetes in the rat, including volumetric quantitation of the pancreatic islets. Diabetologia 9:178-184

43. Li Z, Karlsson FA, Sandler S (2000) Islet loss and alpha cell expansion in type 1 diabetes induced by multiple low-dose streptozotocin administration in mice. J Endocrinol 165:93-99

44. Ellingsgaard H, Ehses JA, Hammar EB et al (2008) Interleukin-6 regulates pancreatic $\alpha$-cell mass expansion. Proc Natl Acad Sci USA 105:13163-13168

45. Gelling RW, Du XQ, Dichmann DS et al (2003) Lower blood glucose, hyperglucagonemia, and pancreatic $\alpha$ cell hyperplasia in glucagon receptor knockout mice. Proc Natl Acad Sci USA 100:1438-1443

46. Hansen AM, Bödvarsdottir TB, Nordestgaard DN et al (2011) Upregulation of alpha cell glucagon-like peptide 1 (GLP-1) in Psammomys obesus - an adaptive response to hyperglycaemia? Diabetologia 54:1379-1387

47. Kawamori D, Kurpad AJ, Hu J et al (2009) Insulin signaling in $\alpha$-cells modulates glucagon secretion in vivo. Cell Metab 9:350-361

48. Thorel F, Nepote V, Avril I et al (2010) Conversion of adult pancreatic $\alpha$-cells to $\beta$-cells after extreme $\beta$-cell loss. Nature 464:1149-1154

49. Prasadan K, Daume E, Preuett B et al (2002) Glucagon is required for early insulin-positive differentiation in the developing mouse pancreas. Diabetes 51:3229-3236 